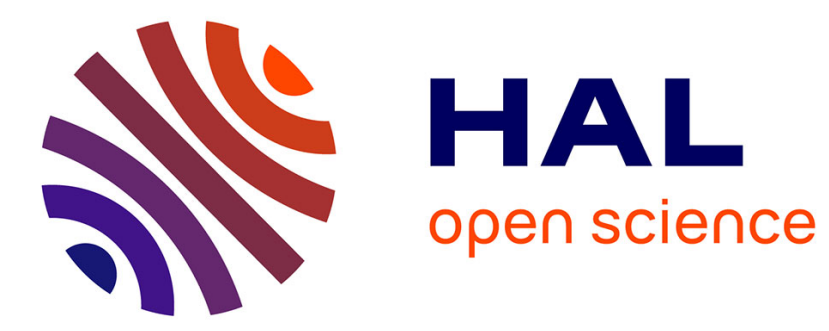

\title{
Bone ingrowth on the surface of endosseous implants. Part 1: Mathematical model
}

\author{
Pedro Moreo, José Manuel García-Aznar, Manuel Doblaré
}

\section{To cite this version:}

Pedro Moreo, José Manuel García-Aznar, Manuel Doblaré. Bone ingrowth on the surface of endosseous implants. Part 1: Mathematical model. Journal of Theoretical Biology, 2009, 260 (1), pp.1. 10.1016/j.jtbi.2008.07.040 . hal-00554503

\section{HAL Id: hal-00554503 https://hal.science/hal-00554503}

Submitted on 11 Jan 2011

HAL is a multi-disciplinary open access archive for the deposit and dissemination of scientific research documents, whether they are published or not. The documents may come from teaching and research institutions in France or abroad, or from public or private research centers.
L'archive ouverte pluridisciplinaire HAL, est destinée au dépôt et à la diffusion de documents scientifiques de niveau recherche, publiés ou non, émanant des établissements d'enseignement et de recherche français ou étrangers, des laboratoires publics ou privés. 


\section{Author's Accepted Manuscript}

Bone ingrowth on the surface of endosseous implants.

Part 1: Mathematical model

Pedro Moreo, José Manuel García-Aznar, Manuel

Doblaré

PII:

S0022-5193(08)00402-5

DOI: doi:10.1016/j.jtbi.2008.07.040

Reference:

YJTBI 5242

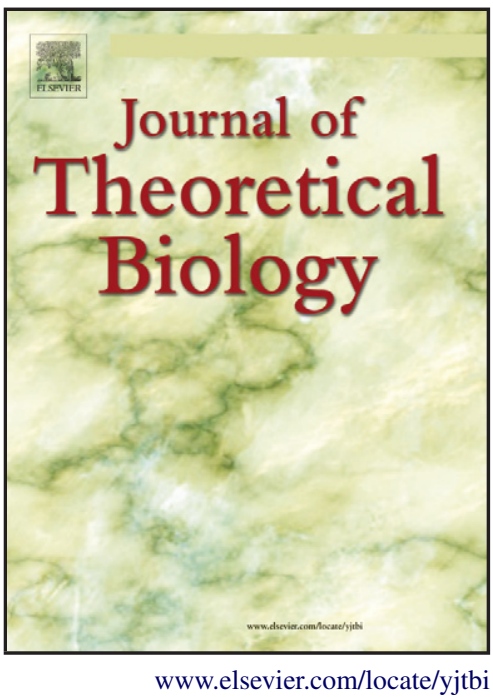

To appear in: $\quad$ Journal of Theoretical Biology

Received date: 2 April 2008

Revised date: 23 June 2008

Accepted date: 29 July 2008

Cite this article as: Pedro Moreo, José Manuel García-Aznar and Manuel Doblaré, Bone ingrowth on the surface of endosseous implants. Part 1: Mathematical model, Journal of Theoretical Biology (2008), doi:10.1016/j.jtbi.2008.07.040

This is a PDF file of an unedited manuscript that has been accepted for publication. As a service to our customers we are providing this early version of the manuscript. The manuscript will undergo copyediting, typesetting, and review of the resulting galley proof before it is published in its final citable form. Please note that during the production process errors may be discovered which could affect the content, and all legal disclaimers that apply to the journal pertain. 


\title{
Bone ingrowth on the surface of endosseous implants. Part 1: Mathematical model
}

\author{
Pedro Moreo, ${ }^{\text {a,b }}$ José Manuel García-Aznar, ${ }^{\text {a,b,* }}$ \\ Manuel Doblaré ${ }^{\mathrm{a}, \mathrm{b}}$ \\ ${ }^{a}$ Group of Structural Mechanics and Materials Modelling, Aragón Institute of \\ Engineering Research (I3A), University of Zaragoza, Zaragoza, Spain \\ ${ }^{\mathrm{b}}$ CIBER-BBN Centro Investigación Biomédica en Red en Bioingeniería, \\ Biomateriales y Nanomedicina, Zaragoza, Spain
}

\begin{abstract}
Osseointegration, understood as an intimate apposition and interdigitation of bone to a biomaterial, is usually regarded as a major condition for the long-term clinical success of bone implants. Clearly, the anchorage of an implant to bone tissue critically relies on the formation of new bone between the implant and the surface of the old peri-implant bone and depends on factors such as the surface microtopography, chemical composition and geometry of the implant, the properties of the surrounding bone and the mechanical loading process. The main contribution of this work is the proposal of a new mathematical framework based on a set of reactiondiffusion equations that try to model the main biological interactions occurring at the surface of implants and is able to reproduce most of the above mentioned biological features of the osseointegration phenomenon. This is a two-part paper. In this first part, a brief biological overview is initially given, followed by the presentation and discussion of the model. In addition, two-dimensional finite element
\end{abstract}


simulations of the bone-ingrowth process around a dental implant with two different surface properties are included to assess the validity of the model. Numerical solutions show the ability of the model to reproduce features such as contact/distance osteogenesis depending upon the specific surface microtopography. In Part 2 (Moreo et al., 2008), two simplified versions of the whole model are proposed. An analytical study of the stability of fixed points as well as the existence of travelling wave type solutions has been done with both simplified models, providing a significant insight into the behaviour of the model and giving clues to interpret the effectiveness of recently proposed clinical therapies. Futhermore, we also show that, although the mechanical state of the tissue is not directly taken into account in the model equations, it is possible to analyse in detail the effect that mechanical stimulation would have on the predictions of the model. Finally, numerical simulations are also included in the second part of the paper, with the aim of looking into the influence of implant geometry on the osseointegration process.

Key words: Osseointegration, Implant microtopography, Bone implant, Finite element simulation

\section{Introduction}

The number of different types of bone implants and prostheses that are currently being used in clinical practice is great and follows an increasing trend. Perhaps, we could cite dental implantation as the area that has most benefited from the significant innovation and progressive development of bone implants in recent years. The achieved popularity of dental implants relies

\footnotetext{
* Corresponding author. Phone: (+34) 976761912 Fax: (+34) 976762578 E-mail address: jmgaraz@unizar.es (J.M. García-Aznar)
} 
on the impressive clinical results obtained with very high long term success rates (Schmitt and Zarb, 1993; Naert et al., 2000; Haas et al., 2002). However, these convincing clinical achievements, that are shared in general by other types of bone implants such as hip or knee prostheses, are not correlated with an equivalent degree of understanding of the basic mechanisms of peri-implant bone healing. Actually, key information about the biomechanical and biological function of bone implants is still lacking. As far as biomechanics is concerned, perhaps the only well-established fact is the relation between excessive early micromotion and the formation of a fibrous capsule instead of an osseointegrated interface (Pilliar et al., 1986; S $\phi$ balle et al., 1992a,b; Brunski, 1999; Cullinane et al., 2003). The information about the influence of the frequency, amplitude and type of loading on new bone formation is nevertheless still incomplete, despite abundant in vitro and in vivo experimental works (Szmukler-Moncler et al., 1998; Pavlin and Gluhak-Heinrich, 2001). Regarding biology, the different phases and most important concepts of peri-implant bone healing are currently well determined (Davies, 2003; Marco et al., 2005). However, important details about the influence mechanisms of factors such as the implant material or surface microtopography still need further research.

Current implantology research is focused on the design of devices that enhance and accelerate bone healing, lead to an interfacial matrix with adequate structure and properties and therefore allow faster recuperation and earlier loading of the implant (Puleo and Nanci, 1999). Different approaches can be distinguished, but most of them are based on a proper modification of a certain property of the surface: physicochemical, morphological or biochemical. Among the different methods of surface modification, two of them stand out because of their current popularity. In first place, alterations in surface 
microtopography are used to influence cell and tissue responses (Brunette, 1988; Hayakawa et al., 2002; Schierano et al., 2005). Secondly, biochemical modifications of the surface can also be designed with the aim of controlling the biological reaction at the interface by means of the delivery of specific molecules. This includes, for example, immobilisation of proteins or peptides on the surface of the biomaterial or controlled release of osteogenic growth factors (Lind et al., 1996; Lind, 1998; Elmengaard et al., 2005; Oates et al., 2007) and the coating of implant surfaces with minerals, such as calcium phosphate (Hayakawa et al., 2002). It is clear as well that further progress within these techniques is still needed and this demands deeper knowledge of the biological cascade associated to early bone healing around the implant.

In addition to the extensive experimental research, mathematical models and computational simulations can also provide some insight into these matters. In fact, the majority of the existing works of this type on bone implants have focused on the biomechanical nature of the problem, trying to draw conclusions from the change of the mechanical state of bone after placement of implants, evaluating the influence of mechanical factors such as the geometry of the implant or magnitude of loading and proposing phenomenological models for the study of bone ingrowth or remodelling (Swider et al., 2006; Moreo et al., 2007b; Pérez et al., 2007; Daas et al., 2007; Liao et al., 2008). Although the interest of these works is unquestionable, it is the authors' opinion that mechanobiological models in which specific biological processes coupled with mechanics are modelled together with their influence on the structure and mechanical properties of tissues constitute a richer source of information for the understanding of many problems in biomedical sciences. However, it is a field where not many works exist, being possible to find only a few addressed 
to the study of peri-implant endosseous healing (Geris et al., 2004; Andreykiv et al., 2005; Ambard and Swider, 2006; Liu and Niebur, 2007). We would like to remark that all these works consider in different depth several aspects of the biology of bone healing around implants, but they do not contemplate, or they do it in a superficial manner, the effect of the implant surface topography on biological processes. Only in Andreykiv et al. (2005) the effect of friction due to the finishing of the artificial component was taken into account, but exclusively affecting the mechanical part of the model and not the biology, and in Liu and Niebur (2007) bone ingrowth into a porous coated implant surface was simulated taking into account the porosity of the surface in the geometric model.

Thus, the goal of this contribution is to propose a new biological model for the study of bone ingrowth on endosseous implants that, by means of considering the main biological interactions occurring between the tissue and implant, is able to reproduce several significant features of the osseointegration phenomenon. Unlike other previous models, ours is focused on the early stages of bone healing, taking into account immediate events upon implantation of biomaterials such as platelet activation, what allows reproducing in a simple way the effect of surface microtopography. Slower long-term processes, i.e. bone remodelling, are here contemplated only in a simplified manner. This makes sense if one considers, first, that much effort has already been devoted to the mathematical modelling of bone remodelling (see Doblaré and García-Aznar (2005); Reina et al. (2007) and references therein); second, that it is reported that in many types of bone implants most failures occur within the first year and implant loss is significantly lower in subsequent years (see, for example, Goodacre et al. (1999) for the case of single unit dental implant restorations). 
This indicates that the critical issue for this type of implants is the early bone healing and represents a difference with other types of implants such as cemented hip prostheses, in which long-term failure due to bone resorption caused by stress shielding or crack growth within the cement mantle is a typical phenomenon (Bobyn et al., 1992). In order to validate the model, two different strategies have been followed. In first place, computational simulations using the finite element method have been performed, obtaining results in qualitative agreement with experiments. In addition, mathematical analyses of two different simplified versions of the model have been done, from which interesting conclusions about the global behaviour of the model can be drawn, that are again in the line of what the experiments dictate.

The work is organised in two articles. In this first article, a brief overview of the biology of bone healing is provided, followed by the presentation and discussion of the complete model. Moreover, numerical simulations of bone healing around a dental implant are shown, where some features of the model can be evaluated. Next, in the second article presented in Part 2 (Moreo et al., 2008), an analysis is performed where the stability of fixed points and the existence of travelling wave-type solutions are studied in two simplified versions of the model. From this analysis, great insight into the behavior of the model is gained. In particular, we have focused on the effect that mechanical stimulation can have on the migration of osteogenic cells. Finally, we also include another numerical simulation of bone ingrowth around a dental implant with a very particular geometry, characterised by having grooves on the surface of the threads. 


\section{Mathematical modelling of bone ingrowth}

\subsection{Brief biological overview of peri-implant bone healing}

It is the purpose of this section to supply the reader with a very concise — therefore incomplete - biological description of peri-implant bone healing, sufficient for the modelling purposes of this paper. For a detailed description of the process we refer the reader to Davies (2003); Marco et al. (2005); Puleo and Nanci (1999); Brunski (1999); Joos et al. (2006) and the extensive number of references therein, from which the following description has been extracted.

In first place, the surgical procedure, necessary to drill a cavity in the host bone and place the implant, leads to inevitable surgical trauma and damage to blood vessels, followed by the filling of the bone cavity by blood. Immediately upon placement, proteins from blood and tissue fluids are adsorbed to the surface of the implant (Sela et al., 2007). Platelets become activated after contacting with the surface (Nygren et al., 1997a,b) and release a number of growth factors, such as platelet-derived growth factor (PDGF) and transforming growth factor beta (TGF- $\beta$ ) among many others. These growth factors have been shown to stimulate the migration and proliferation of bone marrow derived-cells as well as the proliferation of human osteoblasts (Linkhart et al., 1996; Dimitriou et al., 2005; Kark et al., 2006). Note that an increase in the implant surface microtopography with an appropriate surface roughness can enhance protein adsorption, promoting platelet adhesion and activation, eventually leading to an acceleration of the global healing process (Park et al., 2001; Kikuchi et al., 2005). At the same time, a fibrin network is formed through the well known process of hemostasis. Next, local ischemia due to cessation 
of circulation gives rise to necrosis and a subsequent inflammatory reaction is triggered. Both neutrophils and macrophages reach the site of injury along a chemotactic gradient and are in charge of the removal of necrotic tissue. In parallel, a new peri-implant vascular network starts to form by means of the well-known mechanism of angiogenesis (Lakey et al., 2000).

After these initial events, osteogenic cells coming from the surface of the old host bone migrate through the remnants of the clot towards the surface of the implant and differentiate into osteoblasts, that will later synthesise bone matrix. This phase can be enhanced by the presence of growth factors (Linkhart et al., 1996) and is also influenced by the mechanical state of the tissue. Actually, moderate mechanical stimulation of cells can enhance osseointegration (Rubin and McLeod, 1994) by promoting differentiation of osteogenic cells into osteoblasts and increasing the secretion of growth factors (Pavlin et al., 2000; Pavlin and Gluhak-Heinrich, 2001), but excessive levels of tensile or deviatoric stresses can also induce the formation of a not desirable fibrous tissue around the implant (Jones et al., 1995; Jasty et al., 1997). The global importance of this phase, sometimes referred to as osteoconduction, is crucial and has been highlighted in Davies (2003). It is necessary at this point to remark that new bone always grows by apposition, that is, by deposition of matrix on a preexisting surface. Since osteoblasts become trapped in the own matrix that they secrete and are no longer able to move, becoming osteocytes, formation of new bone on a surface clearly depends on the continuous migration of osteogenic cells to the surface which differentiate into osteoblasts and secrete bone matrix. Hence the importance of the osteoconduction phase.

When the osteogenic cells reach the implant surface and differentiate, a new phase starts where bone matrix formation is carried out by osteoblasts. Usu- 
ally, rapid woven bone formation takes place first to restore continuity, even though its mechanical properties are lower than those of lamellar bone due to the random orientation of collagen fibers (Probst and Spiegel, 1997). Woven bone is eventually replaced by mature lamellar bone in a final bone remodelling phase that takes place at a considerable slow rate compared to the previously mentioned events. One final consideration should be done that refers to the place where bone is laid down. Until the moment we have assumed that new bone forms first on the implant surface. In this case osteogenesis proceeds from the implant to the host bone and is described as contact osteogenesis (Davies, 2003). However, that is only the first possibility since bone can also be deposited directly on the surface of the host bone in the peri-implant site. Note that in this case osteoconduction is not so critical since bone surfaces constitute a source of osteogenic cells that now do not have to migrate until reaching the implant. In this second case osteogenesis proceeds from the host bone towards the implant, that now becomes surrounded by bone, and is therefore designated as distance osteogenesis (Davies, 2003). Rough implant microtopography has been found experimentally to enhance osteoconduction and, therefore, contact osteogenesis. On the other hand, distance osteogenesis can be expected with polished surfaces and cortical host bone (Berglundh et al., 2003).

\subsection{Mathematical model}

We adopt a continuum approach and, consequently, are interested in the spatio-temporal evolution of the volumetric concentration of each specie. Therefore, our model is based upon the fundamental conservation law for the con- 
centration of each specie $Q=Q(\mathbf{x}, t)$ at time $t$ and spatial position $\mathbf{x}$ :

$$
\frac{\partial Q}{\partial t}=-\nabla \cdot \mathbf{J}_{Q}+f_{Q}
$$

where $\mathbf{J}_{Q}$ is the flux (rate of outgoing matter per unit area) of specie $Q$ and $f_{Q}$ the rate of net production of $Q$.

The different variables of the model can be classified into three groups: cell densities, growth factor concentrations and matrix volume fractions. We have considered three different types of cells: platelets, osteogenic cells and osteoblasts, whose respective densities will be denoted by $c, m$ and $b$. The explicit inclusion of platelets is new in this kind of applications and, as will be shown later, is necessary to account for the early stages of bone healing. Note that $c$ stands for the density of the total population of platelets, activated and not. A wide diversity of growth factors and other signalling molecules are known to play a role in the mediation of bone healing mechanisms (Dimitriou et al., 2005), but a model in which a large number of them were individually taken into account, as well as being extremely complex and confusing, would be completely impractical due to the lack of quantitative experimental results needed to fit the parameters. This is why we have preferred to gather all the growth factors into two generic types: the first one, with concentration denoted by $s_{1}$, corresponds to the release of activated platelets (PDGF, TGF- $\beta$ ), whereas the second one, $s_{2}$, represents the set of signalling molecules secreted by osteogenic cells and osteoblasts (BMPs, TGF- $\beta$ superfamily). The extracellular matrix can be composed of three different structures: first, the fibrin network, whose volume fraction is denoted by $v_{f}$, that is assumed to be the only starting component since we do not address the problem of coagu- 
lation; second, woven or inmature bone, $v_{w}$, that is laid down by osteoblasts and, third, lamellar or mature bone, $v_{l}$, that comes from remodelling of woven bone. Finally, the concentration of adsorbed proteins, $p$, appears in the equations but is not a model variable since its value is assumed to be known a priori as a function of the microtopography of the implant surface. It reaches its maximum value at the surface of the implant and decreases very fast as we move away from it, taking value zero in the rest of the domain (Nygren et al., 1997a).

With this, we can particularise the evolution of each cell population density as follows:

Platelets, $c(\mathbf{x}, t)$

$$
\frac{\partial c}{\partial t}=\nabla \cdot\left[D_{c} \nabla c-H_{c} c \nabla p\right]-A_{c} c
$$

The contribution to the cell flux is random dispersal. Thus it has been here modelled as a first approximation by a linear diffusion term with coefficient $D_{c}$, and the cell adhesion to the implant surface. Platelet adhesion has been found experimentally to depend on the microtopography of the surface that alters the concentration of adsorbed proteins to the implant surface (Nygren et al., 1997a; Park et al., 2001). Therefore, it has been modelled as a linear "taxis" term, depending on the gradient of $p$ with coefficient $H_{c}$. A high platelet concentration is assumed at the beginning and thus the only kinetic term comes from cell removal due to inflammatory mechanisms with linear rate $A_{c}$.

Osteogenic CELLS, $m(\mathbf{x}, t)$ 


$$
\begin{aligned}
\frac{\partial m}{\partial t} & =\nabla \cdot\left[D_{m} \nabla m-m\left(B_{m 1} \nabla s_{1}+B_{m 2} \nabla s_{2}\right)\right] \\
& +\underbrace{\left(\alpha_{m 0}+\frac{\alpha_{m} s_{1}}{\beta_{m}+s_{1}}+\frac{\alpha_{m} s_{2}}{\beta_{m}+s_{2}}\right) m\left(1-\frac{m}{N}\right)}_{\text {Proliferation }}-\underbrace{\frac{\alpha_{m b} s_{1}}{\beta_{m b}+s_{1}} m}_{\text {Differentiation }}-\underbrace{A_{m} m}_{\text {Death }}
\end{aligned}
$$

Osteogenic cell flux comes from random cell movement that can be biased by the presence of growth factors. Mathematically this is modelled by means of linear diffusion, with coefficient $D_{m}$, and linear chemotaxis along gradients of the growth factors $s_{1}$ and $s_{2}$ with coefficients $B_{m 1}$ and $B_{m 2}$ (Dimitriou et al., 2005; Kark et al., 2006; Lee et al., 2006; Fiedler et al., 2006). For the kinetics, there is a proliferative term consisting of a logistic growth with a natural linear rate $\alpha_{m 0}$ that can be enhanced by the presence of $s_{1}$ and $s_{2}$ (Kark et al., 2006); phenotypic differentiation into osteoblasts is stimulated by growth factor $s_{1}$ (Linkhart et al., 1996; Dimitriou et al., 2005); and natural cell death is assumed to be produced with a linear rate $A_{m}$.

Osteoblasts, $b(\mathbf{x}, t)$

$$
\frac{\partial b}{\partial t}=\frac{\alpha_{m b} s_{1}}{\beta_{m b}+s_{1}} m-A_{b} b
$$

Osteoblasts remain on the surface of the bone matrix they are secreting (Davies, 2003) and therefore we can assume that there is no flux of this cellular type. The kinetics has a source term of differentiation from the osteogenic phenotype and a decay term representing differentiation into osteocytes $A_{b}$.

Now we present the equations that characterise the evolution of each growth factor concentration: in first place, $s_{1}$, secreted by platelets, and, next, $s_{2}$, 
secreted by osteogenic cells and osteoblasts.

GENERIC GROWTH FACTOR $1, s_{1}(\mathbf{x}, t)$

$$
\frac{\partial s_{1}}{\partial t}=\nabla \cdot\left[D_{s 1} \nabla s_{1}\right]+\left(\frac{\alpha_{c 1} p}{\beta_{c 1}+p}+\frac{\alpha_{c 2} s_{1}}{\beta_{c 2}+s_{1}}\right) c-A_{s 1} s_{1}
$$

Random dispersal of the growth factor is modelled with a linear diffusion term with coefficient $D_{s 1}$. The first kinetic term takes into account the secretion of $s_{1}$ by platelets (Bolander, 1992; Bostrom, 1998) that depends on the degree of activation. Platelet activation in turn is assumed to be fostered by the concentration of adsorbed proteins $p$ and the own growth factor $s_{1}$ (Park et al., 2001). There is also a natural decay of the growth factor with rate $A_{s 1}$.

GENERIC GROWTH FACTOR $2, s_{2}(\mathbf{x}, t)$

$$
\frac{\partial s_{2}}{\partial t}=\nabla \cdot\left[D_{s 2} \nabla s_{2}\right]+\frac{\alpha_{m 2} s_{2}}{\beta_{m 2}+s_{2}} m+\frac{\alpha_{b 2} s_{2}}{\beta_{b 2}+s_{2}} b-A_{s 2} s_{2}
$$

The structure of the equation is completely equivalent to the one of $s_{1}$, although in this case there are two source terms corresponding to secretion of $s_{2}$ by osteogenic cells and osteoblasts. This secretion is enhanced by the own growth factor $s_{2}$ (Linkhart et al., 1996; Dimitriou et al., 2005).

Finally, the evolution of the volume fractions of each component of the matrix are shown below:

FibRin NETWORK VOLUME FRACTION, $v_{f}(\mathbf{x}, t)$

$$
\frac{\partial v_{f}}{\partial t}=-\frac{\alpha_{w} s_{2}}{\beta_{w}+s_{2}} b v_{f}\left(1-v_{w}\right)
$$


Initially the whole volume between bone and implant is assumed to be filled with a fibrin network and $v_{f}$ takes value 1 . Therefore the only kinetic term comes from partial substitution of the fibrin network by woven bone matrix, that is, secretion of new bone by osteoblasts, stimulated by $s_{2}$ (Rosier et al., 1998). Additionally, it is reasonable to consider that the rate of bone secretion takes its maximum value when there is no formed bone $\left(v_{f}=1\right)$ and decreases as the fibrin network is substituted progressively by bone, until reaching a null value when $v_{w}=1$. Consequently, the rate of fibrin adsorption is zero when the fibrin concentration is zero, which is logical and necessary to avoid the prediction of unrealistic negative concentrations.

WOVEn BONE VOLUME FRACTION, $v_{w}(\mathbf{x}, t)$

$$
\frac{\partial v_{w}}{\partial t}=\frac{\alpha_{w} s_{2}}{\beta_{w}+s_{2}} b v_{f}\left(1-v_{w}\right)-\gamma v_{w}\left(1-v_{l}\right)
$$

Woven bone formation is taken into account by the first term, that was explained in the previous paragraph and describes the formation of woven bone that replaces the initial fibrin network. Note that the secretion of woven bone is stopped when its volume fraction reaches the maximum value, 1.0, avoiding the appearance of unrealistic volume fractions larger than 1.0. The second term is a very simple way of considering remodelling of woven bone into lamellar bone.

LAMELLAR BONE VOLUME FRACTION, $v_{l}(\mathbf{x}, t)$

$$
\frac{\partial v_{l}}{\partial t}=\gamma v_{w}\left(1-v_{l}\right)
$$


Finally, the only contribution to the evolution of lamellar bone comes from remodelling of woven bone. Note also that bone remodelling stops when the totality of woven bone has turned into lamellar bone, as wanted.

\section{Numerical simulation of bone ingrowth around a dental implant}

As discussed in the Introduction, the use of endosseous dental implants in clinical dentistry and maxillofacial surgery has expanded during the last two decades. Originally conceived as a foundation for dental prostheses, nowadays endosseous implants are not only used to restore missing teeth, but also to support devices for orthodontic anchorage, distraction osteogenesis, craniofacial reconstructions and nasal prostheses. Additionally, the amount of experimental work devoted in recent years to the study of bone ingrowth around implants has been mostly carried out with dental implants, what facilitates the task of modelling. However, from the point of view of mathematical modelling, qualitative comparisons between predictions and experimental results are many times the only way of validating biological mathematical models. In any case, these two factors, the growing utilisation of dental implants and the relative abundance of experimental results, at least compared to other types of bone implants, have inclined us to perform numerical simulations of bone healing around dental implants as a way to validate the model.

\subsection{Description of the simulation}

As a first approach, we propose a simple two dimensional simulation in a domain that reproduces the cavity between the host bone and two threads of 
a screw-shaped dental implant (see Fig. A.1). In particular, we have chosen a typical implant geometry characterised by threads with inclined walls. The equations have been solved with two different levels of concentration of adsorbed proteins: $p=0.5 \mu \mathrm{g} / \mathrm{mm}^{-2}$ at the surface of the implant, simulating the case of a high microtopography surface implant, and $0.1 \mu \mathrm{g} / \mathrm{mm}^{-2}$, in the case of an implant of low surface microtopography. These values fall within the range of experimental measurements of plasma proteins adsorption on titanium surfaces (Sela et al., 2007) and were imposed at the nodes belonging to the surface of the implant. Moreover, $p$ was assumed to decrease linearly with the distance to the implant surface, reaching value zero at a distance of 0.1 $\mathrm{mm}$. In the rest of the domain situated farther than $0.1 \mathrm{~mm}, p$ took value zero. The reason to simulate with two different values of protein adsorption lies in the fact that we want to show the ability of the model to reproduce one of the most relevant features of peri-implant bone healing, which is the difference between contact and distance osteogenesis depending on the implant surface properties, a matter of the utmost importance in the design of new models of implants. We recall here that implants with surfaces characterised by a high microscopic roughness tend to enhance the formation of bone on the surface of the implant, as opposed to polished or low microtopography implants, where the front of ossification typically moves forward from the host bone towards the implant (Berglundh et al., 2003; Davies, 2003).

As initial conditions, we have considered a concentration of $2.510^{8}$ platelets $/ \mathrm{ml}$, being this high value characteristic of blood (Ganong, 2005), and residual concentrations of osteogenic cells and osteoblasts of $10^{3}$ cells $/ \mathrm{ml}$. Both growth factors are also present at the initial time at a very low concentration of 1 $\mathrm{ng} / \mathrm{ml}$. Zero flux boundary conditions have been applied for all the species of 
model at the surface of the implant and the host bone, except for the concentration of osteogenic cells, that was fixed to $210^{5}$ cells $/ \mathrm{ml}$ at the surface of bone during the first 14 days. The healing period that was simulated consisted of twelve months, more than sufficient in clinical practice to obtain a full osseointegration of the implant and achieve a high degree of remodelling of woven bone into lamellar bone.

The full model has been numerically solved by means of the finite element method, using second order spatial interpolation with eight-node Serendip elements, a generalised trapezoidal method for the integration of temporal derivatives (Hughes, 2000) and a Newton-Raphson implicit scheme with full linearisation of the residual vector for the treatment of the nonlinearities (Zienkiewicz and Taylor, 2000). This formulation has been implemented in an UEL subroutine of the commercial software ABAQUS 6.6. The model parameter values were estimated from the literature as discussed in detail in the Appendix.

\subsection{Results}

From the results of the simulations, we must highlight in first place the substantial difference early found in the density of platelets $c$ and the concentration of the growth factor $s_{1}$ depending on the microtopography. In Fig. A.2 it can be observed that only one day after implantation the high concentration of adsorbed proteins on the surface of the high microtopography implant leads to an increase in the number of platelets near the surface, compared to the situation of a low microtopography implant, where the density of platelets is almost uniform. Actually, an almost 4-fold variation in the concentration of platelets 
at the very surface of the implant was obtained between the two types of surfaces, what corresponds with the range of experimental observations (Park et al., 2001; Kikuchi et al., 2005). This alteration of platelet concentration was expected, since $H_{c}$ was precisely chosen in such a way that such an increase took place when the implant surface microtopography, i.e. the concentration of adsorbed proteins, was changed from low to high. This increase in platelet concentration and activation leads to not only a higher concentration of $s_{1}$ after 14 days of healing, but also to a gradient of this growth factor, being its concentration markedly higher near the implant surface and decreasing as we move away (see Fig. A.3a). On the other hand, a low surface microtopography does not favour the formation of this gradient, as we appreciate in Fig. A.3b, where a variation of only $10 \%$ is obtained along the whole cavity.

It is evident that this early discrepancy between the two types of implants will strongly condition the subsequent healing phases, since, for instance, the migration and invasion of the cavity between bone and implant by osteogenic cells is stimulated by the gradient of $s_{1}$ and their proliferation fostered by the level of concentration of the growth factor. Differences in the migration of osteogenic cells can be appreciated in Fig. A.4. After only 3 days we observe that in the case of a rough (high microtopography) implant the density of osteogenic cells is particularly high near the surface, due to the high concentration of the growth factor $s_{1}$ at the surface, while in the case of the polished (low microtopography) implant a propagating front of cells is moving away from the surface of the host bone. After 7 and 14 days this trend continues: cells invade the cavity from the host bone with the polished implant and from both the host bone and the surface of the implant with the rough implant. Note that in the third and fourth weeks the number of osteogenic cells ceases 
raising, since they start differentiating into osteoblasts.

In Figs. A.5 and A.6 the temporal evolution of the volume fraction of lamellar bone has been depicted. Note again that significant differences appear between the two microtopographies. In the case of the rough implant (Fig. A.5), we observe that the model predicts the formation of new bone from the surface of the implant towards the inside of the cavity, which is commonly denoted as contact osteogenesis. This phenomenon is especially clear during the first month after implantation, since it is in this period when a more pronounced gradient in the volume fraction of lamellar bone develops. It is noteworthy that an ossification front also propagates from the surface of the peri-implant bone directed to the implant surface, since the surface of bone is in any case an important source of osteogenic cells. However, this second mechanism leads to a more constant and slow bone ingrowth. We could say that contact osteogenesis is responsible for the very early formation of new bone on the surface of the implant, what ensures a fast mechanical stability and prevents at the same time the formation of a fibrous capsule, but it is the host bone, acting as a source of osteogenic cells, that guarantees the full ossification of the chamber between bone and implant by means of distance osteogenesis. The coexistence of these two ossification mechanisms was observed experimentally in a rough SLA implant surface by Berglundh et al. (2003) and is evident in our simulations from the observation of the results of Fig. A.5 after one and two months of healing. With respect to the time needed to achieve full osseointegration, almost the whole chamber is filled with a volume fraction of lamellar bone greater than 0.8 after four months, increasing this value to 0.875 after six months and 0.95 after the whole year (not shown).

In the case of the low microtopography implant, the features of the ossification 
process are noticeably different. In first place, the mechanism that inevitably prevails is distance osteogenesis, as shown in Fig. A.6 after healing periods of two weeks and one month. Observe that the rate of bone formation during this initial phase is appreciably slower than in the previous situation. Actually, the volume fraction of lamellar bone after one month reaches a value of 0.3 at the surface of bone, whereas with the rough implant values of 0.4 were already obtained along the whole surface of the implant at that very moment, what is in agreement with experimental observations of Puleo and Nanci (1999), where a difference of $30 \%$ in the rate of bone formation was found between contact and distance osteogenesis. Another interesting issue is the fact that the fraction of bone is now quite uniform along the chamber, what can be explained by the absence of contact osteogenesis, that clearly leads to a more uneven distribution. Finally, the global levels of lamellar bone volume fraction achieved after four, six and twelve months are in general terms comparable to the obtained with the high microtopography implant, although smaller in all cases by a $5-10 \%$ amount.

\section{Discussion}

A biological model able to reproduce several important features of peri-implant bone formation has been here presented. As the most important novel feature, we must emphasise the inclusion of the platelet cellular type and the associated secreted signalling molecules. This enables a careful examination of the early stages of osseointegration and a study of the influence of implant surface properties on the whole process of bone healing. In particular, we have focused on the influence of surface microtopography, which has been found experimen- 
tally to be a determinant factor on osteogenesis (Lossdörfer et al., 2004) and had not been considered in previous mechanobiological models of peri-implant bone ingrowth. Its effect has been taken into account in an indirect way, by means of considering the dependence of platelet activation and aggregation on the density of adsorbed plasma proteins on the implant surface, which is determined a priori as a function of the microtopography. Although other possibilities could be proposed for this aim, this one stands out because of its conceptual simplicity and the abundant information regarding the relation between surface topography and protein adsorption existing in the literature.

However, we must admit that this part of the model is just an approximation to the actual physics and biology of platelet behaviour and, consequently, there are a number of limitations associated to the chosen approach. First, note that the distance from the implant at which $p$ becomes zero, $0.1 \mathrm{~mm}$, implicitly is another model parameter. To be physically realistic, this value must be sufficiently small, since it can be expected that the influence of the implant surface is not noticeable far away from it. Nevertheless, note that the gradient of $p$ obviously depends on this distance, so the fit of parameter $H_{c}$ eventually depends on the choice of the distance. Secondly, there are various experimental works reporting that the migration of cells in response to gradients of chemoattractants not only depends on the gradient but also on the average concentration: at higher concentration levels the ability of cells to sense such gradients is reduced (see Schneider and Haugh (2005) for fibroblasts and Fiedler et al. (2006) for mesenchymal cells). This phenomenon is also expected to happen with platelets in response to the concentration of adsorbed proteins and has not been considered in the model, constituting another limitation of the formulation. Next, the effects of platelet activation have been taken into 
account in a rather simplified way. The first of these effects is the increase of growth factor secretion, which has been modelled as a source term for $s_{1}$ (Eq. (5)) dependent on $p$. Another is the loss of mobility of platelets after activation, which translates into aggregation and adhesion. The net effect of the flux terms of Eq. (2) is responsible for this behaviour in our model. However, it is clear that in further versions of this work a more elaborated activation model would be desirable. To this end, the explicit discrimination in the formulation between non-activated and activated platelets, with a law regulating the transition from one state to the other, could help. Finally, it is to be noted that the continuum approach based on a reaction-diffusion equation used to model platelet behaviour is near its limit of validity, due to the reduced number of cells. All these reflections stress the need of further refinement of this part of the model in the future.

In second place, as it has been shown in the finite element simulation of Section 3, the full model is in agreement with the most important well-established concepts of endosseous healing (Davies, 2003): bone matrix is synthesised only by osteoblasts; bone only grows by apposition, that is, by deposition of matrix on a preexisting surface; and bone matrix has no inherent capacity to grow. The first feature is automatically satisfied from the consideration of Eq. (8), where the formation of new woven bone depends on the density of osteoblasts $b$. The other two can be verified from the results of the simulations where there is always an ossification front towards the implant or coming from its surface, but never isolated islands of newly formed bone emerge. Moreover, the model is able to reproduce the two basic ways osteoblasts have to lay down new bone matrix around endosseous implants: distance and contact osteogenesis. This distinction goes back to Osborn and Newesely (1980) and its reproduction is a 
very desirable property of any mathematical model for bone ingrowth around implants. Our model specifically predicts the predominant laying down of new bone on rough implant surfaces and on the surface of the host bone in the case of implants with a low microtopography, which agrees with the experimental observations (see Berglundh et al. (2003) and references therein). To the authors' knowledge, this is the first time that this feature has been simulated by a model of this type. Finally, the results of the model are in general agreement with the clinical observations in terms of time needed to achieve the different levels of osseointegration. In this regard, we must admit that a detailed quantitative validation of the temporal evolution of the different biological processes is not possible, mostly due to the inherent variability of the speed of each process, what translates into significant differences between the available experimental works. However, to show that the results fall within the physiological range, we can cite the results of Sennerby et al. (1993), where the first signs of hard tissue formation were noticed after one week and that the whole process of remodelling was completed six weeks to three months after insertion of the implants in rabbits. In Roberts (1988) it is established that the approximate ratio in the bone healing time between rabbits and humans is $1: 3$, therefore the predictions of our model for bone ingrowth at humans seem to be within the expected interval.

Nevertheless, there are some features of peri-implant bone ingrowth that the model is not able to reproduce. One of the most relevant limitations of the model has to do with the shape of the ossification front. Usually, it adopts an irregular shape (see for example Berglundh et al. (2003); Götz et al. (2004)), whereas our model predicts the formation of an ossification front with a more regular shape. This is the result of contemplating in the model only the in- 
fluence of growth factors on the formation of bone and differentiation of cells, but not, at least explicitly, the effects of mechanics and/or angiogenesis. Other mathematical models that incorporate these effects present a more irregular distribution of bone (Gómez-Benito et al., 2005; Geris et al., 2004, 2008).

It is also interesting to discuss the different phases of peri-implant bone healing that have been considered in the model. The first one in the temporal cascade of biological events that follow the placement of an endosseous implant is hemorrhage and formation of a blood clot. This has not been considered explicitly in the model, since the starting point for the simulations is the already formed fibrin network. We think nevertheless that this simplification does not take away significant predictive capabilities from the model. Activation of platelets and the subsequent release of growth factors play, on the contrary, a major role in the model and their inclusion has been evidently justified by the results, as discussed before. The following event in the sequence would be inflammation that again has been neglected in this work. The reason is that the main result of this biological process, that is, clot and necrotic tissue demolition, is not easy to model theoretically, while at the same time is not necessary for a correct simulation of the following healing phases. In parallel to inflammation, angiogenesis takes place and it is necessary as the only means of providing nutrients supply to the peri-implant healing compartment. In Geris et al. (2008), the role of angiogenesis in bone fracture healing was considered. In the present contribution, by not modelling it, we are implicitly assuming that it always occurs successfully. However, it is true that the formation of a new vascular network can be influenced by implant surface properties (Matsuo et al., 1999), although few experimental data exist and the understanding of the biological mechanisms that regulate this influence is still reduced, what 
makes very difficult the modelling task. This remains being a limitation of the model and constitutes a future line of research.

The next three phenomena, osteoconduction, new bone formation and bone remodelling, are not only crucial in the whole process of peri-implant bone ingrowth, but also critical in the more general field of bone healing and regeneration (Davies, 2003), and have been considered in detail in the model, especially the two first ones. The main criticism that must be done regarding this part of the model has to do with the no inclusion of mechanical effects. Bone remodelling depends indeed on mechanical loading, but, as discussed in the Introduction, this phase is not usually the critical point for the clinical result of dental implants. The speed and direction of cell migration can also be affected by the mechanical stress of the surrounding tissue, what has been taken in (Moreo et al., 2007a), and by the damage of the tissue (Gómez-Benito et al., 2005; García-Aznar et al., 2007). In our case, however, we consider more important the chemotactic effect of growth factors and therefore neglect these mechanical influences. Furthermore, osteogenic cells differentiation can also be influenced by the mechanical state of the tissue, in addition to growth factors. The assumption that these cells always differentiate into the osteoblastic phenotype is not true under high deviatoric or tensile loading, where endochondral ossification of fibrous tissue formation can appear (Claes et al., 1998). This is usual in cases with early excessive mechanical loading of the implant and hence the validity of the model is restricted to scenarios of moderate loading. However, we think that it is much more interesting to study how bone ingrowth can be enhanced in a favourable situation, rather than focusing on a very extreme situation due to severe early mechanical loading, scenario that a priori is well known to be harmful for the osseointegration of an implant and 
must be avoided in any case.

There are two additional issues that must be addressed to finish the discussion. The first is the large number of parameters comprised in the model. Some of them have been directly obtained from the literature, others have been estimated from experimental results and a third group of parameters have been taken from other computational works or have been fitted by means of numerical simulations. The difficulty of finding adequate values for the parameters due to the lack of direct experimental measurements is a weak point, shared to some extent by many mechanistic models.

The final comment is related to the suitability of the boundary conditions applied in the finite element simulation. At the implant surface zero flux boundary conditions were imposed for all the variables, which is logical since neither cells nor growth factors are capable of migrating through it. However, the situation is not so clear in the case of the host bone surface, especially when the diffusion of growth factors is contemplated. Bone always has a certain level of porosity, which in the case of trabecular bone can be significant. It is therefore reasonable to consider that growth factors can partially diffuse through the host bone, away from the cavity. However, the porosity of bone is markedly lower than that of the fibrin network, the structure that predominates at the early stages of healing when the influence of growth factors on cell behaviour is more important. Thus, only a small fraction of the growth factor is expected to diffuse through the bone and the zero flux boundary condition for its concentration, albeit not corresponding exactly with the real physical situation, can be considered to be sufficiently accurate for the purposes of this work. However, it is true that this boundary condition can be partially responsible for the high levels of concentration of $s_{1}$ at the corners between the implant 
and the bone (Fig. A.3).

In summary, we have presented a new mathematical model for the study of bone ingrowth that presents some novel features compared to preexisting models. In particular, the incorporation of the activation of platelets in the formulation has provided a simple way to take into account the influence of implant surface properties. Although the extreme complexity of the biology of bone healing has forced us to make important simplifications in order to obtain a tractable model, the obtained results show the ability of the model to reproduce many important features of this important biological process.

The present work opens interesting new lines of research related to the design of bone implants. In first place, the proposed framework is perfectly valid to study, by means of computational simulations, the effect of some techniques that are being nowadays investigated to improve bone healing, such as surface functionalisation or controlled release of osteogenic growth factors. In second place, the formulation can be used to analyse the effect of the geometry of the implant on the osseointegration process. Note that the inclusion of certain geometrical features, such as grooves on the surface of the implant threads, can certainly alter the development of bone formation. In last place, moderate mechanical loading can enhance determined biological processes, therefore stimulating the formation of bone, what can be easily studied with our model. The last two issues, i.e. the influence of the geometry and mechanical loading, have been addressed in detail in Part 2 of this paper (Moreo et al., 2008). 


\section{Acknowledgments}

The authors gratefully acknowledge the research support of the Spanish Ministry of Health through the CIBER-BBN and the Spanish Ministry of Science and Technology through Research Projects DPI2006-14669 and DPI200609692 and the FPU graduate research fellowship program.

\section{References}

Ambard, D., Swider, P., 2006. A predictive mechano-biological model of the bone-implant healing. Eur. J. Mech. A-Solids 25, 927-937.

Andreykiv, A., Prendergast, P. J., van Keulen, F., Swieszkowski, W., Rozing, P. M., 2005. Bone ingrowth simulation for a concept glenoid component design. J. Biomech. 38, 1023-1033.

Bailón-Plaza, A., van der Meulen, M. C. H., 2001. A mathematical framework to study the effects of growth factor influences on fracture healing. J. Theor. Biol. 212, 191-209.

Berglundh, T., Abrahamsson, I., Lang, N. P., 2003. De novo alveolar bone formation adjacent to endosseous implants. A model study in the dog. Clin. Oral Impl. Res. 14, 251-262.

Bobyn, J. D., Mortimer, E. S., Glassman, A. H., Engh, C. A., Miller, J. E., Brooks, C. E., 1992. Producing and avoiding stress shielding: laboratory and clinical observations of non-cemented total hip arthroplasty. Clin. Orthop. Relat. Res. 274, 79-96.

Bolander, M. E., 1992. Regulation of fracture repair by growth factors. Proc. Soc. Exp. Biol. Med. 200, 165-170. 
Bostrom, M. P., 1998. Expression of bone morphogenetic proteins in fracture healing. Clin. Orthop. 355S, 116-123.

Brunette, D. M., 1988. The effects of implant surface topography on the behaviour of cells. Int. J. Oral Maxillofac. Implants 3, 231-246.

Brunski, J. B., 1999. In vivo bone response to biomechanical loading at the bone/dental-implant interface. Adv. Dent. Res. 13, 99-119.

Cai, A. Q., Landman, K. A., Hughes, B. D., 2007. Multi-scale modeling of a wound-healing cell migration assay. J. Theor. Biol. 245, 576-594.

Claes, L. E., Heigele, C. A., Neidlinger-Wilke, C., Kaspar, D., Seidl, W., Margevicius, K. J., Augat, P., 1998. Effects of mechanical factors on the fracture healing process. Clin. Othop. Relat. Res. 355, S132-147.

Coffey, R. J., Russell, W. E., Barnard, J. A., 1990. Pharmacokinetics of TGF beta with emphasis on effects on liver and gut. Ann. N. Y. Acad. Sci. 593, $285-291$.

Cullinane, D. M., Salisbury, K. T., Alkhiary, Y., Eisenberg, S., Gerstenfeld, L., Einhorn, T. A., 2003. Effects of the local mechanical environment on vertebrate tissue differentiation during repair: does repair recapitulate development? J. Exp. Biol. 206, 2459-2471.

Daas, M., Dubois, G., Bonnet, A. S., Lipinski, P., Rignon-Bret, C., 2007. A complete finite element model of a mandibular implant-retained overdenture with two implants: Comparison between rigid and resilient attachment configurations. Med. Eng. Phys. doi:10.1016/j.medengphy.2007.02.005.

Dasch, J. R., Pace, D. R., Waegell, W., Inenaga, D., Ellingsworth, L., 1989. Monoclonal antibodies recognizing transforming growth factor-beta. Bioactivity, neutralization and transforming growth factor-beta 2 affinity purification. J. Immunol. 142, 1536-1541.

Davies, J. E., 2003. Understanding peri-implant endosseous healing. J. Dental 
Educ. 67, 932-949.

Dimitriou, R., Tsiridis, E., Giannoudis, P. V., 2005. Current concepts of molecular aspects of bone healing. Injury, Int. J. Care Injured 36, 1392-1404.

Doblaré, M., García-Aznar, J. M., 2005. On the numerical modelling of growth, differentiation and damage in structural living tissues. Arch. Comput. Meth. Engng. 11, 1-45.

Edelman, E. R., Nugent, M. A., Karnovsky, M. J., 1993. Perivascular and intravenous administration of basic fibroblast growth factor: vascular and solid organ deposition. Proc. Natl. Acad. Sci. U.S.A. 90, 1513-1517.

Elmengaard, B., Bechtold, J. E., S $\phi$ balle, K., 2005. In vivo study of the effect of RGD treatment on bone ongrowth on press-fit titanium alloy implants. Biomaterials 26, 3521-3526.

Farré, J., Roura, S., Prat-Vidal, C., Soler-Botija, C., Llach, A., Molina, C. E., Hove-Madsen, L., Cairó, J. J., Gòdia, F., Bragós, R., Cinca, J., BayesGenis, A., 2007. FGF-4 increases in vitro expansion rate of human adult bone marrow-derived mesenchymal stem cells. Growth Factors 25, 71-76.

Fiedler, J., Brill, C., Blum, W. F., Brenner, R. E., 2006. IGF-I and IGF-II stimulate directed cell migration of bone-marrow-derived human mesenchymal progenitor cells. Biochem. Biophys. Res. Commun. 345, 1177-1183.

Fiedler, J., Etzel, N., Brenner, R. E., 2004. To go or not to go: migration of human mesenchymal progenitor cells stimulated by isoforms of PDGF. J. Cell. Biochem. 93, 990-998.

Fiedler, J., Leucht, F., Waltenberger, J., Dehio, C., Brenner, R. E., 2005. VEGF and PlGF-1 stimulate chemotactic migration of human mesenchymal progenitor cells. Biochem. Biophys. Res. Commun. 344, 561-568.

Friedl, P., Zänker, K. S., Bröcker, E. B., 1998. Cell migration strategies in 3-D extracellular matrix: differences in morphology, cell matrix interactions, and 
integrin function. Micros. Res. Tech. 43, 369-378.

Ganong, W. F., 2005. Review of medical physiology, 22nd Edition. McGrawHill.

García-Aznar, J. M., Kuiper, J. H., Gómez-Benito, M. J., Doblaré, M., Richardson, J. B., 2007. Computational simulation of fracture healing: influence of interfragmentary movement on the callus growth. J. Biomech. 40, $1467-1476$.

Geris, L., Andreykiv, A., Oosterwyck, H. V., Sloten, J. V., van Keulen, F., Duyck, J., Naert, I., 2004. Numerical simulation of tissue differentiation around loaded titanium implants in a bone chamber. J. Biomech. 37, 763769.

Geris, L., Gerisch, A., Sloten, J. V., Weiner, R., Oosterwyck, H. V., 2008. Angiogenesis in bone fracture healing: a bioregulatory model. J Theor Biol 251, 137-158.

Gómez-Benito, M. J., García-Aznar, J. M., Kuiper, J. H., Doblaré, M., 2005. Influence of fracture gap size on the pattern of long bone healing: a computational study. J. Theor. Biol, 235, 105-119.

Goldsmith, H. L., Turitto, V. T., 1986. Rheological aspects of thrombosis and haemostasis: basic principles and applications. Thromb. Haemost. 55, 415435.

Goodacre, C. J., Kan, J. Y., Rungcharassaeng, K., 1999. Clinical complications of osseointegrated implants. J. Prosthet. Dent. 81, 537-552.

Goodman, P. D., Barlow, E. T., Crapo, P. M., Mohammad, S. F., Solen, K. A., 2005. Computational model of device-induced thrombosis and thromboembolism. Ann. Biomed. Eng. 33, 780-797.

Gruler, H., Bültmann, B. D., 1984. Analysis of cell movement. Blood cells 10, $61-77$. 
Götz, H. E., Müller, M., Emmel, A., Holzwarth, U., Erben, R. G., Stangl, R., 2004. Effect of surface finish on the osseointegration of laser-treated titanium alloy implants. Biomaterials 25, 4057-4064.

Haas, R., Polak, C., Fürhauser, R., Mailath-Pokorny, G., Dörtbudak, O., Watzek, G., 2002. A long-term follow-up of 76 Bränemark single-tooth implants. Clin. Oral Implants Res. 13, 38-43.

Hayakawa, T., Yoshinarib, M., Kibac, H., Yamamotoc, H., Nemotoa, K., Jansen, J. A., 2002. Trabecular bone response to surface roughened and calcium phosphate (Ca-P) coated titanium implants. Biomaterials 23, 10251031.

Hughes, T. J. R., 2000. The Finite Element Method, 1st Edition. Dover Publications, Inc.

Izadpanah, R., Trygg, C., Patel, B., Kriedt, C., Dufour, J., Gimble, J. M., Bunnell, B. A., 2006. Biological properties of mesenchymal stem cells derived from bone marrow and adipose tissue. J. Cell. Biochem. 99, 1285-1297.

Jasty, M., Bragdon, C., Burke, D., O’Connor, D., Lowenstein, J., Harris, W. H., 1997. In vivo skeletal response to porous-surfaced implants subjected to small induced motions. J. Bone Joint Surg. Am. 79, 707-714.

Jones, D., Leivseth, G., Tenbosh, J., 1995. Mechano-reception in osteoblastlike cells. J. Biochem. Cell Biol. 73, 525-532.

Joos, U., Wiesmann, H. P., Szuwart, T., Meyer, U., 2006. Mineralization at the interface of implants. Int. J. Oral Maxillofac. Surg. 35, 783-790.

Kark, L. R., Karp, J. M., Davies, J. E., 2006. Platelet releasate increases the proliferation and migration of bone marrow-derived cells cultured under osteogenic conditions. Clin. Oral Impl. Res. 17, 321-327.

Kikuchi, L., Park, J. Y., Victor, C., Davies, J. E., 2005. Platelet interactions with calcium-phospate-coated surfaces. Biomaterials 26, 5285-5295. 
Lakey, L., Akella, R., Ranieri, J. P., 2000. Angiogenesis: implications for tissue repair. In: Tissue engineering. Toronto, em squared Inc., pp. 137-142.

Lee, D. H., Park, B. J., Lee, M. S., Lee, J. W., Kim, J. K., Yang, H. C., Park, J. C., 2006. Chemotactic migration of human mesenchymal stem cells and MC3T3-E1 osteoblast-like cells induced by COS-7 cell line expressing rhBMP-7. Tissue Eng. 12, 1577-1586.

Liao, S., Tong, R., Dong, J., 2008. Influence of anisotropy on peri-implant stress and strain in complete mandible model from ct. Comput. Med. Imaging Graph. 32, 53-60.

Lind, M., 1998. Growth factor stimulation of bone healing. effects on osteoblasts, osteomies and implant fixation. Acta Orthop. Scand. Suppl. 283, $2-37$.

Lind, M., Overgaard, S., Nguyen, T., Ongpipattanakul, B., Bunger, C., S $\phi$ balle, K., 1996. Transforming growth factor- $\beta$ stimulates bone ongrowth. hydroxyapatite-coated implants studied in dogs. Acta Orthop. Scand. 67, $611-616$.

Linkhart, T. A., Mohan, S., Baylink, D. J., 1996. Growth factors for bone growth and repair: IGF, TGF $\beta$ and BMP. Bone 19, 1S-12S.

Liu, X., Niebur, G. L., 2007. Bone ingrowth into a porous coated implant predicted by a mechano-regulatory tissue differentiation algorithm. Biomechan. Model Mechanobiol. doi:10.1007/s10237-007-0100-3.

Lossdörfer, S., Schwartz, Z., Wang, L., Lohmann, C. H., Turner, J. D., Wieland, M., Cochran, D. L., Boyan, B. D., 2004. Microrough implant surface topographies increase osteogenesis by reducing osteoclast formation and activity. J. Biomed. Mater. Res. A 70, 361-369.

Maini, P. K., McElwain, D. L. S., Leavesley, D. I., 2004. Traveling wave model to interpret a wound-healing cell migration assay for human peri- 
toneal mesothelial cells. Tissue Eng. 10, 475-482.

Marco, F., Milena, F., Gianluca, G., Vittoria, O., 2005. Peri-implant osteogenesis in health and osteoporosis. Micron 36, 630-644.

Mareddy, S., Crawford, R., Brooke, G., Xiao, Y., 2007. Clonal isolation and characterization of bone marrow stromal cells from patients with osteoarthritis. Tissue Eng. 13, 819-829.

Matsuo, M., Nakamura, T., Kishi, Y., Takahashi, K., 1999. Microvascular changes after placement of titanium implants: scanning electron microscopy observations of machined and titanium plasma-sprayed implants in dogs. J. Periodontol. 70, 1330-1338.

Moreo, P., García-Aznar, J. M., Doblaré, M., 2007a. Modeling mechanosensing and its effect on the migration and proliferation of adherent cells. Acta Biomater. doi:10.1016/j.actbio.2007.10.014.

Moreo, P., García-Aznar, J. M., Doblaré, M., 2008. Bone ingrowth on the surface of endosseous implants. Part 2: Influence of mechanical stimulation, type of bone and geometry. J. Theor. Biol. submitted.

Moreo, P., Pérez, M. A., García-Aznar, J. M., Doblaré, M., 2007b. Modelling the mechanical behaviour of living bony interfaces. Comput. Meth. Appl. Mech. Eng. 196, 3300-3314.

Naert, I., Koutsikakis, G., Duyck, J., Quirynen, M., Jacobs, R., van Steenbergue, D., 2000. Biologic outcome of single-implant restorations as tooth replacements: a long-term follow-up study. Clin. Implant Dent. Relat. Res. $2,209-218$.

Nygren, H., Eriksson, C., Lausmaa, J., 1997a. Adhesion and activation of platelets and polymorphonuclear granulocyte cells at $\mathrm{TiO}_{2}$ surfaces. J. Lab. Clin. Med. 129, 35-46.

Nygren, H., Tengvall, P., Lundström, I., 1997b. The initial reactions of $\mathrm{TiO}_{2}$ 
with blood. J. Biomed. Mater. Res. 35, 487-492.

Oates, T. W., Valderrama, P., Bischof, M., Nedir, R., Jones, A., Simpson, J., Toutenburg, H., Cochran, D. L., 2007. Enhanced implant stability with a chemically modified SLA surface: a randomized pilot study. Int. J. Oral Maxillofac. Implants 22, 755-760.

Osborn, J. F., Newesely, H., 1980. Dynamic aspects of the implant-bone interface. In: Dental implants: materials and systems. München, Carl Hanser Verlag, pp. 111-123.

Park, J. Y., Gemmell, C. H., Davies, J. E., 2001. Platelet interactions with titanium: modulation of platelet activity by surface topography. Biomaterials $22,2671-2682$.

Pavlin, D., Dove, S. B., Zadro, R., Gluhak-Heinrich, J., 2000. Mechanical loading stimulates differentiation of periodontal osteoblasts in a mouse osteoinduction model: effect on type I collagen and alkaline phosphatase genes. Calcif. Tissue Int. 67, 163-172.

Pavlin, D., Gluhak-Heinrich, J., 2001. Effect of mechanical loading on periodontal cells. Crit. Rev. Oral Biol. Med. 12, 414-424.

Pilliar, R. M., Lee, J. M., Maniatopopulus, C., 1986. Observations on the effect of movement on bone ingrowth into porous-surfaced implants. Clin. Orthop. Rel. Res. 208, 108-113.

Pérez, M. A., Moreo, P., García-Aznar, J. M., Doblaré, M., 2007. Computational simulation of dental implant osseointegration through resonance frequency analysis. J. Biomechanics doi:10.1016/j.jbiomech.2007.09.013.

Probst, A., Spiegel, H. U., 1997. Cellular mechanisms of bone repair. J. Invest. Surg. 10, 77-86.

Puleo, D. A., Nanci, A., 1999. Understanding and controlling the bone-implant interface. Biomaterials 20, 2311-2321. 
Reina, J. M., García-Aznar, J. M., Domínguez, J., Doblaré, M., 2007. Numerical estimation of bone density and elastic constants distribution in a human mandible. J. Biomech. 40, 828-836.

Roberts, W. E., 1988. Bone-tissue interface. J. Dent. Educ. 52, 802-809.

Rosier, R. N., O'Keefe, R. J., Hicks, D. G., 1998. The potential role of transforming growth factor beta in fracture healing. Clin. Orthop. 355S, 294-300.

Rubin, C. T., McLeod, K. J., 1994. Promotion of bony ingrowth by frequencyspecific, low amplitude mechanical strain. Clin. Orthop. Relat. Res. 298, $165-174$.

Schenk, R., Hunziker, E. B., 1994. Histologic and ultraestructural features of fracture healing. In: Bone formation and repair. Rosemont, IL: American Academy of Orthopaedic Surgeons, pp. 117-146.

Schierano, G., Canuto, R. A., Navone, R., et al., 2005. Biological factors involved in the osseointegration of oral titanium implants with different surfaces: a pilot study in minipigs. J. Periodontol. 76, 1710-1720.

Schmitt, A., Zarb, G. A., 1993. The longitudinal clinical effectiveness of osseointegrated dental implants for single tooth replacement. Int. J. Prosthodont. 6, 197-202.

Schneider, I. C., Haugh, J. M., 2005. Quantitative elucidation of a distinct spatial gradient-sensing mechanisms in fibroblasts. J. Cell Biol. 171, 883892.

Sela, M. N., Badihi, L., Rosen, G., Steinberg, D., Kohavi, D., 2007. Adsorption of human plasma proteins to modified titanium surfaces. Clin. Oral Implants Res. 18, 630-638.

Sennerby, L., Thomsen, P., Ericson, L. E., 1993. Early tissue response to titanium implants inserted in rabbit bone. part i. light microscopic observations. J. Mater. Sci.-Mater. Med. 4, 240-250. 
Sфballe, K., Brockstedt-Rasmussen, H., Hansen, E. S., Bünger, C., 1992a. Hydroxyapatite coating modifies implant membrane formation. Acta Orthop. Scand. 63(2), 128-140.

S $\phi$ balle, K., Hansen, E. S., Brockstedt-Rasmussen, H., J $\phi$ rgensen, P. H., Bünger, C., 1992b. Tissue ingrowth into titanium and hydroxyapatitecoated implants during stable and unstable mechanical conditions. J. Orthop. Res. 10, 285-299.

Swider, P., Pedrono, A., Mouzin, O., Sфballe, K., Bechtold, J. E., 2006. Biomechanical analysis of the shear behaviour adjacent to an axially loaded implant. J. Biomech. 39, 1873-1882.

Szmukler-Moncler, S., Salama, H., Reingewirtz, Y., Dubruille, J. H., 1998. Timing of loading and effect of micromotion on bone-dental implant interface: review of experimental literature. J. Biomed. Mater. Res. 43, 192-203.

Vander, A., Sherman, J., Luciano, D., 1998. Human Physiology: The mechanisms of Body Function. WCB Mc-Graw Hill, Boston, MA.

Zienkiewicz, O. C., Taylor, R. L., 2000. The Finite Element Method, 5th Edition. Vol. 2: Solid Mechanics. Butterworth-Heinemann.

\section{A Model parameters value estimation}

The parameter values were derived from the literature when possible and estimated when no relevant data were available:

- Platelets: A value of $1.36510^{-2} \mathrm{~mm}^{2}$ /day was taken for the diffusion coefficient $D_{c}$ from Goldsmith and Turitto (1986) and Goodman et al. (2005). Assuming that after one month of healing, only a residual fraction of $10 \%$ of the initial concentration of platelets remains, the cell decay rate $A_{c}$ was 
estimated as 0.067 day $^{-1}$. The "taxis" parameter $H_{c}$ was determined by means of numerical simulations so that a 4 -fold increase in the concentration of platelets at the surface of the implant was obtained when the microtopography was changed from low to high, which is in the range of the experimental observations (Park et al., 2001; Kikuchi et al., 2005). This procedure led to a value of $0.333 \mathrm{~mm}^{4} /($ day $\mu \mathrm{g})$ for $H_{c}$.

- Osteogenic cells flux: A value of $0.133 \mathrm{~mm}^{2} /$ day was taken for the diffusion coefficient $D_{m}$, in the order of magnitude of other computational works (Bailón-Plaza and van der Meulen, 2001; Gómez-Benito et al., 2005; Geris et al., 2008) and within the range of $10^{-8}-10^{-10} \mathrm{~cm}^{2} / \mathrm{s}$, obtained experimentally for most of types of cells (Gruler and Bültmann, 1984; Friedl et al., 1998; Maini et al., 2004; Cai et al., 2007). Several experimental studies have looked into the chemotactic effect on osteogenic cells migration (Fiedler et al., 2004, 2005, 2006; Lee et al., 2006). For example, Lee et al. (2006) reported up to a 1.7 -fold increase in cell speed thanks to this effect. Rough estimates based on these data suggest values for the chemotactic coefficient in the order of $1 \mathrm{~mm}^{2} \mathrm{day}^{-1}(\mathrm{ng} / \mathrm{ml})^{-1}$. Accordingly, $B_{m 1}$ and $B_{m 2}$ were estimated as 0.667 and $0.167 \mathrm{~mm}^{2} \operatorname{day}^{-1}(\mathrm{ng} / \mathrm{ml})^{-1}$, respectively.

- Osteogenic cells and osteoblasts kinetics: From various experimental works (Izadpanah et al., 2006; Mareddy et al., 2007), the rate of cell proliferation can be estimated between 0.3 and 0.5 day $^{-1}$. Moreover, Farré et al. (2007) reported a half reduction in the doubling time of human bone marrow-derived mesenchymal stem cells in cell proliferation experiments, what suggests that the natural cell proliferation rate can be doubled on account of the presence of growth factors. This led us to use values of 0.25 day $^{-1}$ both for $\alpha_{m 0}$ and $\alpha_{m}$. Based on geometrical constraints, Bailón-Plaza and van der Meulen (2001) derived a value for the limiting cell density $N$ of $10^{6}$ cells $/ \mathrm{ml}$. 
Based on the typical lifespan of mesenchymal stem cells (Izadpanah et al., 2006), a value of $210^{-3}$ day $^{-1}$ was determined for $A_{m}$. Quantified rates of cell differentiation are not available and in the absence of experimental data a sensitivity analysis was performed. A value of 0.5 day $^{-1}$ for $\alpha_{m b}$ was found to yield results in agreement with the experimental temporal evolution of the process. Just like in other computational studies (Bailón-Plaza and van der Meulen, 2001; Geris et al., 2008), it was assumed that relatively low values of growth factor concentrations are sufficient to have a significant effect. Therefore, concentrations of $10 \mathrm{ng} / \mathrm{ml}$ were used for $\beta_{m}$ and $\beta_{m b}$ in this work. A similar strategy was used in the rest of equations where similar terms appeared. Finally, a rate of $6.6710^{-3}$ day $^{-1}$ was used for $A_{b}$, related to cell death and differentiation into osteocytes.

- Growth factors: The estimation of $D_{s 1}$ and $D_{s 2}$ has been done on the same basis as in Bailón-Plaza and van der Meulen (2001) and Geris et al. (2008). Basically, the reasoning is based on the fact that the diffusion coefficient of a substance in aqueous solution can be determined from its molecular weight (Vander et al., 1998). This procedure leads to values for the diffusion coefficients in the order of magnitude of $10^{-8} \mathrm{~cm}^{2} / \mathrm{s}$. Furthermore, we have taken into account that the growth factor $s_{1}$ migrates essentially through the remnants of the blood clot and the early granulation tissue, whereas the growth factor $s_{2}$ has to diffuse through the already forming bone matrix, that has a higher density and thus offers a greater resistance to the diffusion. Based on this considerations, values of 0.3 and $0.1 \mathrm{~mm}^{2}$ /day were taken for $D_{s 1}$ and $D_{s 2}$, respectively. Growth factors involved in bone healing have in vivo half-lives in the order of 1 hour (Coffey et al., 1990; Dasch et al., 1989; Edelman et al., 1993). Accordingly, values of 10 day $^{-1}$ were used for $A_{s 1}$ and $A_{s 2}$. No experimental data were available on the secretion rates of 
growth factors, so a range of values was explored numerically and values of $6.6710^{-5}, 10^{-5}, 2.510^{-3}$ and $2.510^{-3} \mathrm{ng} / \mathrm{ml}$ day $^{-1}(\text { cells } / \mathrm{ml})^{-1}$ were finally chosen for $\alpha_{c 1}, \alpha_{c 2}, \alpha_{m 2}$ and $\alpha_{b 2}$, respectively. $\beta_{c 1}$ was estimated as $0.1 \mu \mathrm{g} / \mathrm{mm}^{2}$, so that, with the low microtopography surface, the rate of secretion of $s_{1}$ dependent on the concentration of adsorbed proteins $p$ was half of the maximum value. Finally, $\beta_{c 2}, \beta_{m 2}$ and $\beta_{b 2}$ were chosen as 10 $\mathrm{ng} / \mathrm{ml}$, based on the same considerations of the osteogenic cells kinetics terms.

- Bone formation: In Schenk and Hunziker (1994) it is reported that woven bone filled small holes drilled in rabbit cortical bone six weeks after surgery. Assuming that bone healing in bone-implant gaps proceeds as in the small holes, which is quite reasonable from the examples of the literature (Brunski, 1999), and that the approximate ratio in the bone healing time between rabbits and humans is 1:3 (Roberts, 1988), we should expect a value of $v_{w}$ close to 1.0 after 18 weeks of healing. Rough estimates based on Eq. 7 contemplating this data suggest values of $\alpha_{w}$ in the order of magnitude of $10^{-6}-10^{-7} \mathrm{day}^{-1}$ (cells $\left./ \mathrm{ml}\right)^{-1}$. A value of $10^{-7}$ day $^{-1}(\text { cells } / \mathrm{ml})^{-1}$ was chosen for $\alpha_{w}$ and $10 \mathrm{ng} / \mathrm{ml}$ for $\beta_{w} \cdot \gamma$ was determined by means of numerical simulations, as the value that led to an almost full remodelling, $v_{l} \simeq 0.9$, after 1 year of healing period. 


\section{List of Figures}

A.1 (a) Sketch of the insertion of a screw-shaped dental implant in a drilled cavity of bone, where the computational domain of our simulations is highlighted; (b) Boundary conditions and dimensions of the domain.

A.2 Density of platelets $c\left(\mathrm{x} 10^{9}\right.$ cells $\left./ \mathrm{ml}\right) 1$ day after placement of the implant in the case of an implant with (a) high microtopography and (b) low migrotopography.

A.3 Concentration of growth factor $s_{1}(\mathrm{x} 100 \mathrm{ng} / \mathrm{ml})$ after 14 days in the case of an implant with (a) high microtopography and (b) low microtopography.

A.4 Temporal evolution of the density of osteogenic cells $m$ $\left(\mathrm{x} 10^{6}\right.$ cells $\left./ \mathrm{ml}\right)$ for both types of implants: rough (high microtopography) and polished (low microtopography).

A.5 Temporal evolution of the volume fraction of lamellar bone around an implant with a high surface microtopography.

A.6 Temporal evolution of the volume fraction of lamellar bone around an implant with a low surface microtopography. 


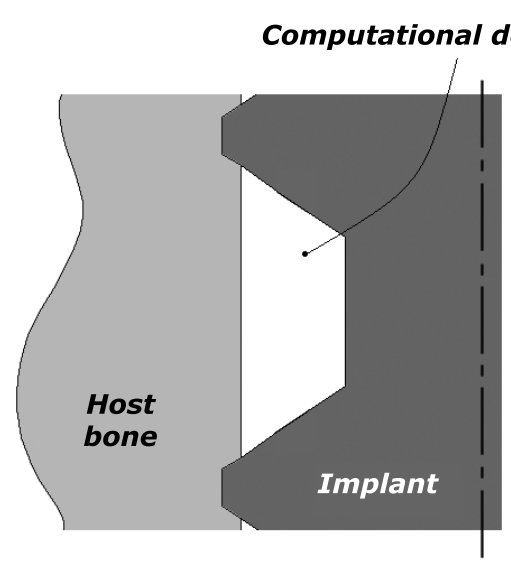

(a)

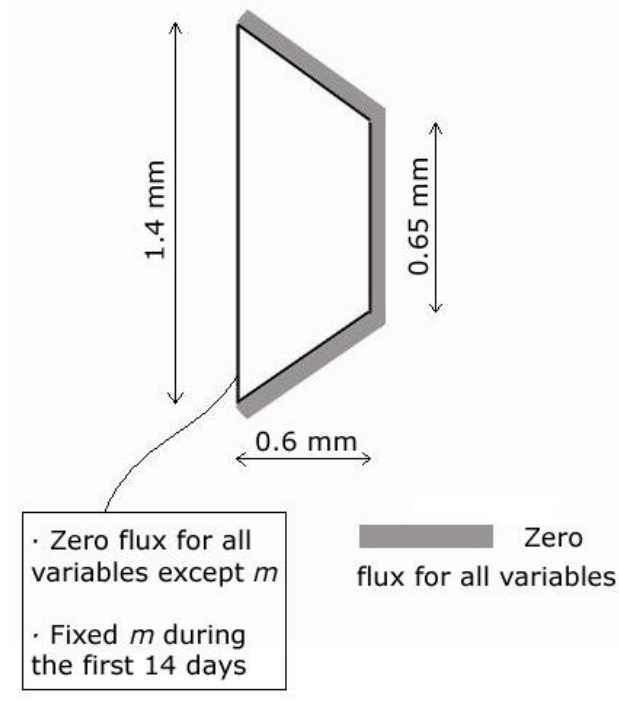

(b)

Figure A.1. (a) Sketch of the insertion of a screw-shaped dental implant in a drilled cavity of bone, where the computational domain of our simulations is highlighted; (b) Boundary conditions and dimensions of the domain. 


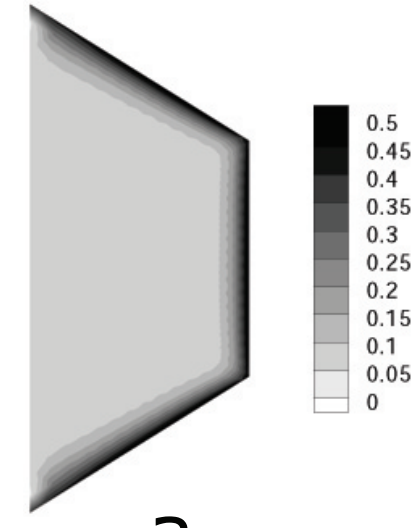

a

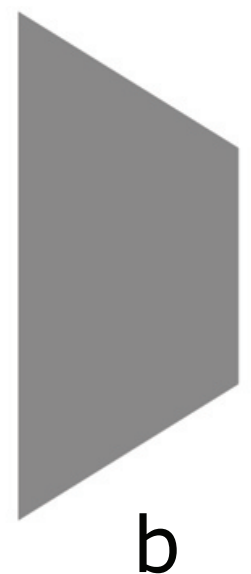

Figure A.2. Density of platelets $c\left(\mathrm{x} 10^{9}\right.$ cells $\left./ \mathrm{ml}\right) 1$ day after placement of the implant in the case of an implant with (a) high microtopography and (b) low migrotopography. 


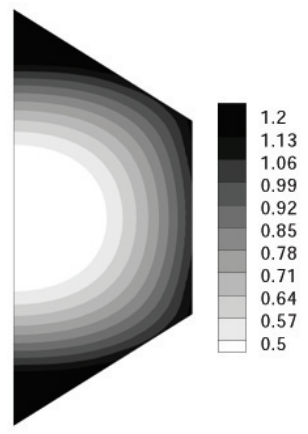

a

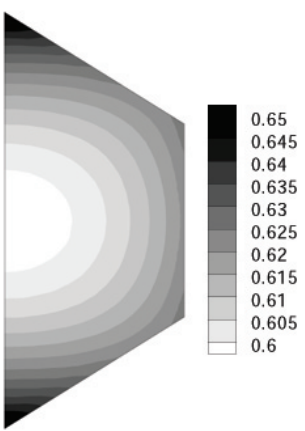

b

Figure A.3. Concentration of growth factor $s_{1}(\mathrm{x} 100 \mathrm{ng} / \mathrm{ml})$ after 14 days in the case of an implant with (a) high microtopography and (b) low microtopography. 


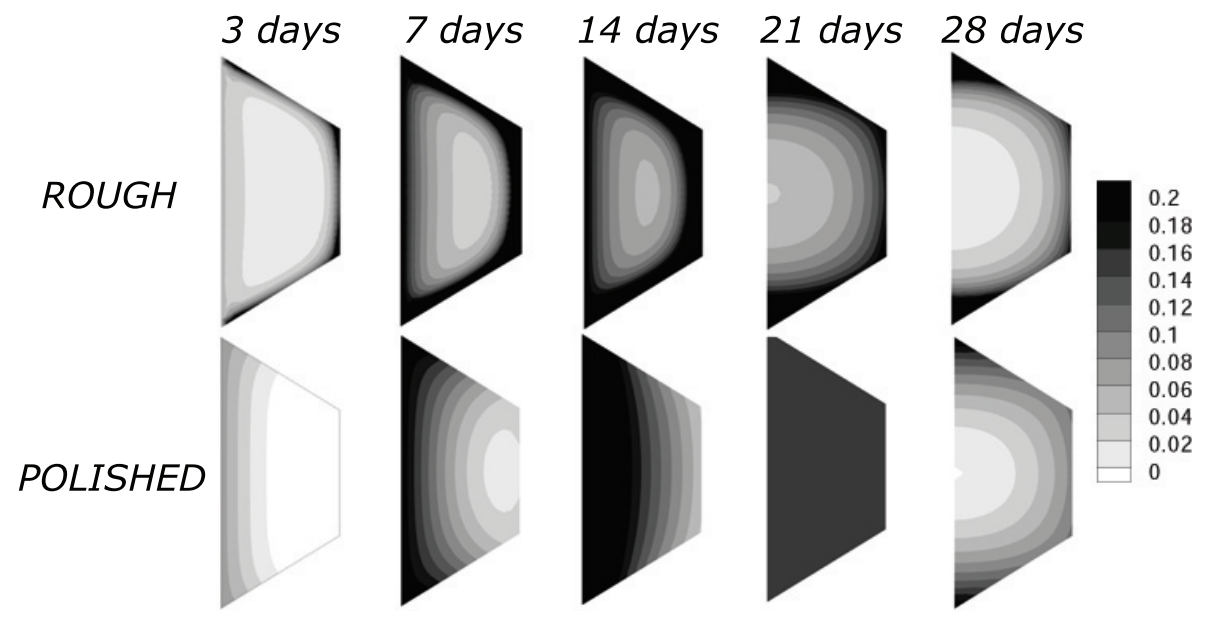

Figure A.4. Temporal evolution of the density of osteogenic cells $m\left(\mathrm{x} 10^{6}\right.$ cells $\left./ \mathrm{ml}\right)$ for both types of implants: rough (high microtopography) and polished (low microtopography). 


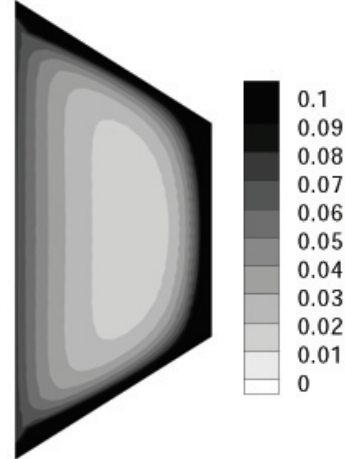

2 weeks

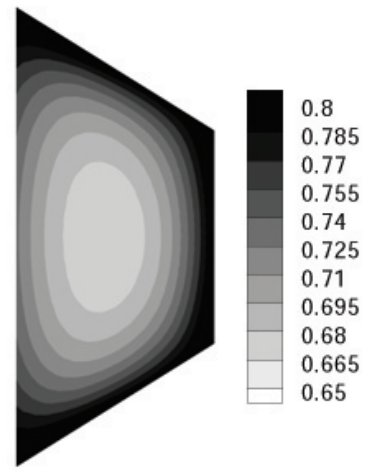

3 months
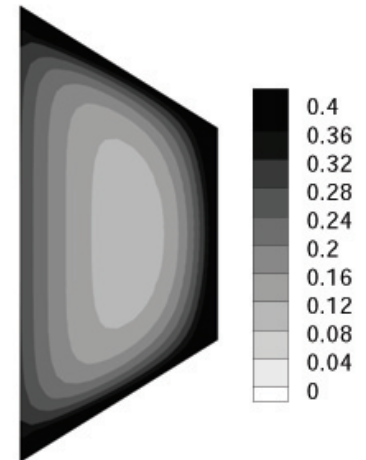

1 month
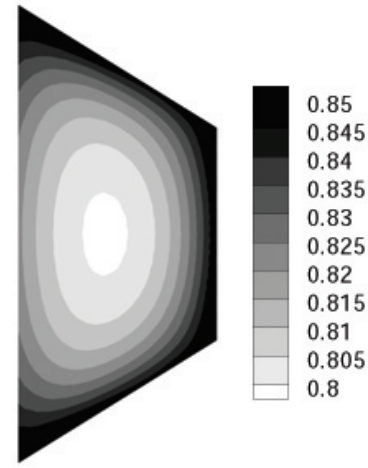

4 months

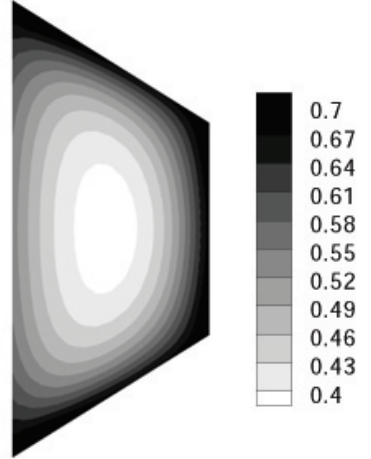

\section{2 months}

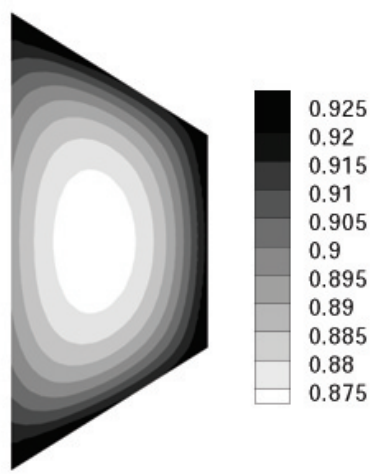

6 months

Figure A.5. Temporal evolution of the volume fraction of lamellar bone around an implant with a high surface microtopography. 


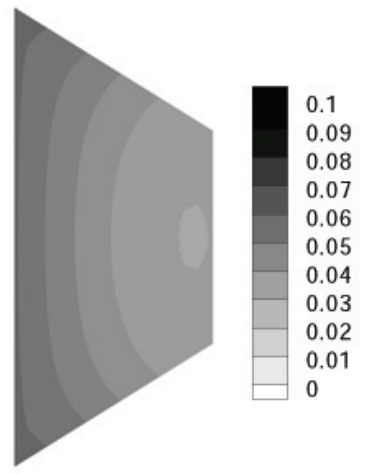

2 weeks
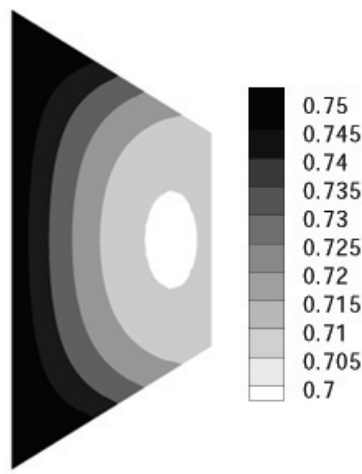

3 months

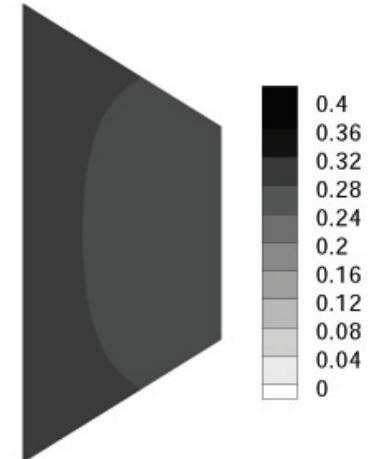

1 month

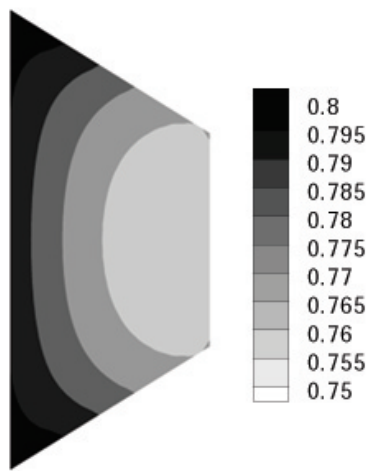

4 months

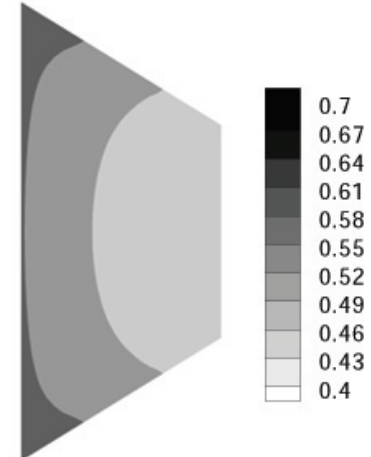

\section{2 months}

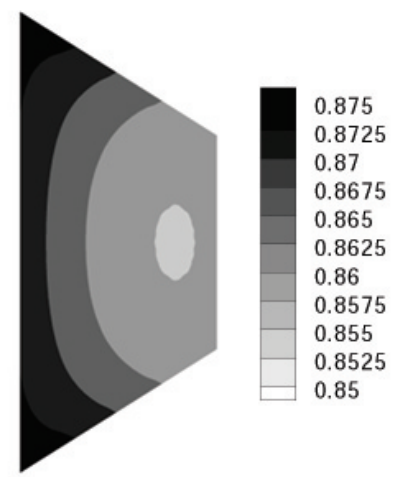

6 months

Figure A.6. Temporal evolution of the volume fraction of lamellar bone around an implant with a low surface microtopography. 